\title{
ANÁLISE \\ CONTEXTUAL \\ DE RESUMOS \\ ACADÊMICOS \\ GRÁFICOS \\ DE BIOLOGIA \\ E DE QUÍMICA
}

\section{ANÁLISIS CONTEXTUAL DE RESÚMENES ACADÉMICO GRÁFICOS DE BIOLOGÍA Y DE QUÍMICA}

CONTEXTUAL ANALYSIS OF BIOLOGY AND CHEMISTRY ACADEMIC GRAPHICAL ABSTRACTS

Cristiane Salete Florek*

Universidade Federal de Santa Maria

RESUMO: O resumo acadêmico gráfico (RAG) é uma prática discursiva não regular, realizada no contexto acadêmico e que, quando ocorre, coexiste com o resumo acadêmico (RA) nos Sumários de periódicos científicos e na versão HTML do artigo acadêmico, materializando-se, principalmente, pela combinação dos modos semióticos verbal e visual. Neste trabalho, à luz da Análise Crítica de Gêneros (MEURER, 2002; BHATIA, 2004; MOTTA-ROTH, 2006, 2008), que nos permite estudar um texto com base na investigação crítica de seu contexto, apresentamos os resultados da análise contextual realizada em RAGs das áreas de Biologia e de Química por meio de i) entrevistas com pesquisadores das áreas investigadas; e ii) análise documental. Os resultados demonstram que, de modo geral, o RAG: i) aparece em destaque, apresentando uma natureza publicitária, que busca atrair a atenção do leitor; ii): sumariza o tema e as principais descobertas da pesquisa científica; e iii) não substitui o RA.

PALAVRAS-CHAVE: Resumo Acadêmico Gráfico. Análise Crítica de Gênero. Multimodalidade. Análise Contextual. 
RESUMEN: El resumen académico gráfico (RAG) es una práctica discursiva no regular, celebrada en el contexto académico. Cuando el RAG se produce, coexiste con el resumen académico (RA) en los resúmenes de las revistas científicas y en la versión HTML del artículo académico, materializándose principalmente por la combinación de los modos semióticos verbales y visuales. Este trabajo presenta, a la luz del Análisis Crítico de Género (MEURER, 2002; BHATIA, 2004; MOTTA-ROTH, 2006, 2008), que nos permite estudiar un texto basado en la investigación crítica de sus métodos de producción y consumo, los resultados de un análisis contextual en RAGs de las áreas de Biología y Química a través: i) entrevistas con investigadores de las áreas estudiadas; y ii) análisis documental. Los resultados muestran que, en general, el RAG: i) se destaca por presentar un carácter publicitario, que busca atraer la atención del lector; ii): resume el tema y los principales resultados de la investigación científica; y iii) no sustituye la RA.

PALABRAS CLAVE: Resumen académico gráfico. Análisis Crítico de Género. Multimodalidad. Análisis contextual.

ABSTRACT: The Graphical Abstract (GA) is a non-regular discursive practice held in the academic context, and that, when occurs, coexists with the academic abstract (AA) in the table of contents of scientific journals, and in HTML versions of academic articles, materializing by the combination of the verbal and visual semiotics. In this paper, in the light of the Critical Analysis genres (MEURER, 2002; BHATIA, 2004; MOTTA-ROTH, 2006, 2008), which allow us to study a text based on the investigation of its context's critical research, we present the results of the contextual analysis of GAs in the areas of Biology and Chemistry. This analysis was done by: i) interviews with researchers of the investigated areas; and ii) documentary analysis. Results show that, in general, GA: i) is highlighted by presenting an advertising nature, which seeks to attract the reader's attention; ii): summarizes the topic and the main findings of scientific research; and iii) does not replace the academia abstract (AA).

KEYWORDS: Graphical Abstracts. Genre Critical Analysis. Multimodality. Contextual Analysis.

\section{INTRODUÇÃO}

No contexto acadêmico, onde o fluxo de informações é especialmente amplo e acelerado, o resumo acadêmico (RA) é um gênero que possibilita fazer avaliações rápidas sobre a confiabilidade das informações expostas em um artigo científico (TENOPIR et al., 2013, p. 13), é condição para a aceitação ou não de um trabalho em um evento acadêmico, como um congresso ou um seminário, e, também, acompanha gêneros acadêmicos mais longos, como dissertações, teses, monografias e artigos acadêmicos (MOTTAROTH; HENDGES, 2010). O RA, desse modo, é “[...] a porta de entrada que leva os leitores a lerem um artigo, periódicos científicos a selecionarem contribuições ou organizadores de conferências a aceitarem ou rejeitarem artigos" (LORÉS, 2004, p. 281). Vale destacar, contudo, que o modo de organização das informações (BATHIA, 1993; MOTTA-ROTH; HENDGES, 1996, 2010; SAMRAJ, 2005; AYERS, 2008; GOLEBIOWSKY, 2009, p. ex.) e, especialmente, as modalidades de apresentação do RA (ELSEVIER, 2009; NATURE, 2011; FLOREK; HENDGES, 2013; FLOREK, 2015), não são estáticas e vêm se modificando.

Atualmente, juntamente com o RA, alguns periódicos científicos apresentam um resumo visual (graphical abstract) das principais informações da pesquisa científica (ELSEVIER, 2009; NATURE, 2011). Em estudos prévios (FLOREK; HENDGES, 2013; FLOREK, 2015), denominamos essa nova modalidade de resumir a pesquisa de resumo acadêmico gráfico (doravante RAG).

Em termos históricos, o RAG surge e se mantém por muitos anos como prática exclusiva da área de Química. O primeiro RAG de que se tem conhecimento foi publicado em 1976 pelo periódico científico alemão Angewandte Chemie (NATURE, 2011). Em 1986, o periódico Tetrahedron Letters aderiu a essa prática. Em 1994, o periódico Chemical Communications também adotou o RAG. Em 2002, o RAG surgiu no Journal of the American Chemical Society (JACS) (NATURE, 2011). A partir de 2009, por meio de uma iniciativa de dinamização da apresentação dos resultados da pesquisa científica em periódicos da Editora Elsevier, o RAG ganhou uma certa popularidade e estima em outras áreas do conhecimento (ELSEVIER, 2009) e a adesão de periódicos científicos de outras editoras, como Nature, por exemplo. 
Tecnicamente, o RAG é definido como um resumo simples, conciso e visual das principais conclusões do artigo científico (ELSEVIER, 2014), apresentando uma imagem apelativa (FEMS, 2014) que atraia a atenção do leitor (NATURE, 2014). Linguisticamente, entretanto, devido à escassa bibliografia sobre o assunto, a definição do RAG demanda uma análise pormenorizada, que possibilite especificar a sua natureza e constituição, tanto no que concerne à(s) linguagem(s) que o compõe(m) quanto ao contexto em que é praticado.

No âmbito da Pedagogia de Gêneros (MARTIN, 1999), da Pedagogia dos Multiletramentos (NEW LONDON GROUP, 1996) e da Análise Crítica de Gêneros (MEURER, 2002; BHATIA, 2004; MOTTA-ROTH, 2006, 2008), pressupostos teórico-metodológicos aos quais nos filiamos, estudar o RAG implica refletir sobre como organizamos e empregamos a linguagem para que possamos alcançar nossos objetivos dentro de um determinado contexto social. Trata-se de uma investigação das diversas modalidades semióticas (verbal - oral e escrita, visual, gráfica, sonora, gestual, por exemplo) (NEW LONDON GROUP, 1996; KRESS; VAN LEEUWEN, 1996, 2006; KRESS, 2010) que combinamos discursivamente e dos diferentes significados textuais, sociais e contextuais que materializamos por meio de gêneros discursivos.

Sendo assim, estudar um evento linguístico como o RAG à luz da perspectiva dos gêneros discursivos requer a tomada de consciência do aspecto inerentemente social de toda e qualquer atividade linguística (BAKHTIN, 1986, 2008), o que implica, em termos de análise linguística, uma investigação crítica que estabeleça relações entre o texto e as suas condições de produção, distribuição e consumo, tendo como pano de fundo o momento histórico (MOTTA-ROTH, 2008). A investigação crítica da linguagem poderá nos colocar em contato com as representações da realidade (crenças, ideologias e conhecimentos) que os usuários da linguagem têm em relação ao mundo; com as relações sociais que se estabelecem por meio da interação entre os participantes do discurso e com as identidades sociais (posicionamento ideológico, imagem de si, por exemplo) mobilizadas no ato da comunicação (MEURER, 2002).

Nesse sentido, em termos práticos, estudar um texto demanda um trabalho de averiguação da linguagem em uso e das relações de significado que unem o texto ao seu contexto, analisando os padrões retóricos que permitem identificar um texto como sendo um exemplar de um determinado gênero que pode organizar e gerar “[...] espécies de texto e ações sociais numa complexa e dinâmica relação recíproca” (BAWARSHI; REIFF, 2013, p. 16). Neste artigo, buscamos apresentar, à luz de uma perspectiva crítica de análise de gênero, os resultados da investigação contextual realizada em torno da publicação de RAGs em periódicos científicos de Biologia e de Química.

Primeiramente, apresentamos os princípios teórico-metodológicos que embasam este estudo, dando destaque à Análise Crítica de Gênero e suas teorias fundantes. Em seguida, expomos os procedimentos e as categorias teórico-metodológicas mobilizadas na ánalise do contexto de produção e consumo de RAGs. Posteriormente, apresentamos os resultados da análise dos Sumários e das Instruções para autores de periódicos científicos das áreas de Biologia e de Química e das entrevistas com pesquisadores dessas áreas. Por fim, apresentamos algumas considerações finais sobre este estudo.

\section{PRINCÍPIOS TEÓRICO-METODOLÓGICOS NORTEADORES}

Como dito antes, a perspectiva teórico-metodológica que embasa este estudo é a Análise Crítica de Gênero (doravante ACG). Seguindo os pressupostos da ACG, concebemos a linguagem como um sistema sociossemiótico, pois: i) possui uma estrutura e uma organização que permitem realizar atividades e ações dentro de um contexto específico (HALLIDAY; MATHIESSEN, 2004); ii) dialogicamente, constitui e é constituída pela sociedade; e iii) combina diferentes ações e artefatos sociais potencialmente significativos para construir significados (VAN LEEUWEN, 2005).

Unicamente como sistema, entretanto, a linguagem não existe, ela carece do uso, da sua articulação em discursos (FAIRCLOUGH, 2003, p. 3) para efetivamente expressar os valores e significados das diferentes instituições (MEURER, 2005), apresentando "[...] conhecimentos socialmente construídos de algum aspecto da realidade” (VAN LEEUWEN, 2005, p. 94). Os discursos, contudo, carecem de uma materialização linguística para se manifestarem: os textos, sejam um gesto, uma palavra, uma receita de bolo, ou 
todo um discurso, são caracterizados por uma “[...] determinada organização linguística e uma determinada função social, num determinado contexto histórico-social" (MEURER, 1997, p. 16).

Nesse sentido, a ACG é, de acordo com Motta-Roth (2008), uma perspectiva teórico-metodológica que possibilita analisar a linguagem desde seus níveis textuais até seus níveis contextuais, considerando, assim, as suas diferentes instâncias de materialização e os engendramentos discursivos subjacentes a cada prática linguística. Inspirada nos estudos bakhtinianos (BAKHTIN, 1986, 2008), a ACG entrelaça e expande os conceitos e os métodos da Sociorretórica (MILLER, 1984; BAZERMAN, 1988; SWALES, 1990, 2004; BHATIA, 1993, 2004, p. ex.), da perspectiva sociossemiótica da linguagem, representada pela Linguística Sistêmico-Funcional (LSF) (HALLIDAY; HASAN, 1985, 1989; MARTIN, 1992; HALLIDAY, 1994; MARTIN; ROSE, 2003; HALLIDAY; MATTHIESSEN, 2004, p. ex.) e pela sua decorrente Análise do Discurso Multimodal (ADM) (O'TOOLE, 1994; KRESS; VAN LEEUWEN, 1996, 2006; O’HALLORAN, 2004, p. ex.), e os combina ao componente crítico de análise, oferecido pela Análise Crítica do Discurso (ACD) (FAIRCLOUGH, 1989, 1992, 2003; WODAK; MEYER, 2009, p. ex.).

Em linhas gerais, os estudos de Bakhtin $(1986,2008)$ emprestam para a ACG a perspectiva de que os gêneros se inter-relacionam com o aspecto social da linguagem (MOTTA-ROTH; MARCUZZO, 2010). De acordo com Bakhtin (2011), gêneros são constituídos de uma dimensão linguístico-textual e de outra social. Ambas as dimensões estão vinculadas a uma situação social típica de interação, no âmbito de uma esfera social, com uma finalidade discursiva específica de acordo com seus referentes de autor e destinatário também específicos.

A LSF contribui para a ACG pela sua perspectiva sociossemiótica e por conceber que a linguagem realiza simultaneamente três categorias de significados: ideacionais; interpessoais e contextuais. Os significados ideacionais são responsáveis pela representação dos participantes, processos e circunstâncias envolvidos na atividade discursiva; aos significados interpessoais compete o estabelecimento de relações entre os envolvidos na atividade discursiva; e aos significados textuais cabe revelar qual o papel da linguagem no âmbito da atividade discursiva (HALLIDAY; MATTHIESSEN, 2004).

A ACD aporta para a ACG a percepção crítica de texto, de discurso e de contexto, entendidos como unidades indissociáveis. Além disso, segundo Motta-Roth (2008), o aparato teórico-metodológico da ACD possibilita uma análise do discurso linguisticamente voltada para os aspectos sociais, políticos e ideológicos que perpassam a língua e o discurso.

Por fim, a Sociorretórica contribui para a ACG no sentido de possibilitar identificar as regularidades retóricas do discurso de acordo com seus propósitos comunicativos no seio de comunidades discursivas particulares (MOTTA-ROTH, 2008).

As abordagens teórico-metodológicas que fundamentam a ACG não são nem excludentes nem exclusivas, por isso, em conjunto, possibilitam fundamentar a ACG como teoria que agrega, a um só tempo, três movimentos de análise do discurso, como descrito por Bhatia (2004, p. 4-18): i) textualização da lexicogramática: investigação das estruturas mínimas de um texto e de suas funções dentro de um dado discurso; ii) organização do discurso: análise da organização do discurso a partir dos seus padrões ou regularidades retóricas; e iii) contextualização do discurso: investigação dos contextos institucional, disciplinar, profissional e social do discurso.

Para os fins desta pesquisa, a ACG nos permite investigar as práticas linguísticas atreladas à produção e ao consumo de RAGs em duas diferentes áreas do conhecimento, a Biologia e a Química. Desse modo, pretendemos clarificar, ainda que parcialmente, algumas das condições de produção dos RAGs, de modo que essas informações possam, posteriormente, ser cruzadas com as informações sobre a constituição textual dos RAGs. 


\section{METODOLOGIA}

O universo de análise desta pesquisa compreende: i) duas Grandes Áreas do conhecimento: Ciências Biológicas (Área de Biodiversidade) e Química (Área de Química), escolhidas conforme classificação das áreas do conhecimento da Coordenação de Aperfeiçoamento de Pessoal de Nível Superior (CAPES, 2014)' ;i) quatro diferentes periódicos científicos e documentos sobre a produção e o consumo de RAGs a eles atrelados: 1) Angewandte Chemie; 2) Energy and Environmental Science; 3) Nature Chemical Biology; e 4) Journal of Controlled Release, selecionados seguindo o critério de maior Fator de Impacto, conforme os dados do Journal Citation Reports (JCR) e o indicador Qualis da Coordenação de Aperfeiçoamento de Pessoal de Nível Superior (CAPES); e iii) pesquisadores (professores e alunos de graduação e de pós-graduação) das áreas de Biodiversidade e de Química, da Universidade Federal de Santa Maria (UFSM).

Quanto à escolha do Fator de Impacto e do Qualis como critérios para a seleção dos periódicos científicos que compõem o universo de análise desta pesquisa, é importante que façamos alguns esclarecimentos. Os periódicos científicos, geralmente, são classificados qualitativamente seguindo certos critérios, como o número de citações recebidas pelos artigos acadêmicos neles publicados. Essas avaliações conferem aos periódicos científicos um certo valor em comparação com os demais periódicos científicos da mesma área. Um sistema de classificação de periódicos científicos é o Fator de Impacto, mensurado, por exemplo, pelo Institute for Scientific Information (ISI), de acordo com a base de dados do Journal Citation Reports (JCR) da editora Thomson Reuters (WEB OF SCIENCE, 2014). O cálculo do Fator de Impacto de um periódico científico é o resultado da divisão do número de citações recebidas pelos artigos acadêmicos nele publicados, nos dois anos anteriores à avaliação, pelo número de artigos publicados no periódico científico nesse período (p. ex.: 2015: 62 citações, 250 artigos publicados / 2016: 46 citações, 250 artigos publicados, então, (62 + 46) $\div(250+250)=$ FI 0,216). Existem outras bases estatísticas que geram o Fator de Impacto (SCImago, p. ex.), entretanto, neste estudo, elegemos a base estatística do JCR para obter o Fator de Impacto dos periódicos científicos por ser a mesma base estatística utilizada pela CAPES para classificar os periódicos científicos das áreas do conhecimento selecionadas para esta pesquisa.

No Brasil, o sistema de avaliação utilizado para classificar os periódicos científicos é o indicador Qualis, proposto pela CAPES. O indicador Qualis é um sistema, atualizado anualmente, que relaciona e classifica os veículos utilizados para a divulgação da produção intelectual dos programas de pós-graduação stricto sensu (mestrado e doutorado) quanto ao âmbito da circulação (local, nacional ou internacional) e à qualidade (A, B, C), por área de avaliação (CAPES, 2014). Em algumas áreas do conhecimento, como Biodiversidade e Química, o indicador Qualis é determinado a partir do Fator de Impacto do periódico científico (p. ex.: A1 - Fator de Impacto = ou > 3,800; A2 - Fator de Impacto entre 3,799 e 2,500; B1- Fator de Impacto entre 2,499 e 1,300; B2 - Fator de Impacto entre 1,299 e 0,001$)^{2}$.

Tendo em vista a conjuntura de estratificação dos períodicos científicos, após criteriosa investigação, observamos que o RAG é uma prática ainda bastante restrita e especialmente praticada em periódicos científicos de alto Fator de Impacto. Sendo assim, escolhemos esse critério para a seleção dos periódocos científicos pesquisados neste trabalho, considerando a que classificação do Qualis remetem.

Da mesma forma, é importante que justifiquemos a escolha de pesquisadores da UFSM para a efetivação das entrevistas que compõem este estudo. O motivo desta escolha está associado ao fato de os Programas de Pós-Graduação das áreas de Biodiversidade e de Química dessa instituição de ensino serem bastante representativos dentro de suas áreas do conhecimento. O Programa de PósGraduação em Biodiversidade Animal (doravante PPGBA) da UFSM, nível de mestrado e doutorado, possui conceito CAPES 4 (CATÁlOGO DE CURSOS DE PÓSGRADUAÇÃO UFSM, 2013). O Programa de Pós-Graduação em Química (doravante PPGQ) da UFSM, nível de mestrado e doutorado, possui conceito CAPES 7 (CATÁLOGO DE CURSOS DE PÓS-GRADUAÇÃO

\footnotetext{
${ }^{1}$ Para este estudo, a heterogeneidade das Áreas de Biodiversidade e de Química e a influência mútua entre as Áreas que compõem as Grandes Áreas de Ciências Exatas e da Terra e de Ciências Biológicas (CAPES, 2014) são dados contextuais relevantes, pois podem revelar informações importantes sobre como e por que uma prática discursiva se estabelece e se difunde melhor em certos campos do conhecimento e não em outros.

${ }^{2}$ A classificação de periódicos Qualis B3, B4 e B5 (que não possuem fator de impacto) segue outros critérios estabelecidos pela CAPES, conforme a base de dados em que tais periódicos estão indexados. Os periódicos irrelevantes para a área são classificados no estrato C e não recebem pontuação.
} 
UFSM, 2013), considerado de excelência de nível internacional pelo Comitê Avaliador da CAPES, que em 2007 o declarou como um "[...] programa consolidado com produção científica muito qualificada. Alguns docentes permanentes do Programa têm liderança nacional e internacional. O Programa ocupa posição de destaque mundial na área de Química, de acordo com o Web of Science" (PPGQ, 2014).

O corpus deste estudo englobou: i) quatro Sumários (Table of Contents), referentes aos periódicos científicos selecionados para a pesquisa; ii) quatro Instruções para autores, referentes aos periódicos científicos selecionados para a pesquisa; e iii) onze entrevistas ${ }^{3}$, realizadas com pesquisadores da UFSM (quatro da área de Química e sete da área de Biodiversidade).

Podemos definir os procedimentos metodológicos empregados neste estudo como característicos de uma pesquisa qualiquantitativa de inspiração textográfica (SWALES, 1998). Quali-quantitativa porque procuramos tratar os dados coletados de maneira quantitativa e qualitativa simultaneamente, isto é, mensuramos os dados traduzíveis em números (quantitativamente) e observamos, descrevemos e interpretamos os dados que não podem ser traduzidos em números (qualitativamente). De inspiração textográfica porque, embora não empregue rigorosamente a textografia proposta por Swales (1998), a pesquisa combinou a análise de RAGs com técnicas etnográficas, como entrevistas e análise documental, objetivando descrever o contexto em que um texto é produzido a fim de explicar por que o texto é escrito, por quem, onde e como é escrito, quais os valores socias subjacentes a ele e qual é seu papel em um contexto particular (PALTRIDGE, 2008). A seguir, detalhamos como ocorreu cada etapa da coleta dos dados contextuais referentes à produção e ao consumo de RAGs:

\subsection{ENTREVISTAS}

Em encontros presenciais ou via e-mail, conforme acordo prévio, realizamos entrevistas com pesquisadores das áreas de Química e de Biodiversidade. Optamos pelo uso de questionário semiestruturado para a condução das entrevistas por entendermos, com Manzini (1991, p. 154), que esse tipo de entrevista focaliza um assunto específico para o qual elaboramos um roteiro com perguntas principais que são complementadas por outras questões específicas, conforme as circunstâncias da entrevista demandarem. Sendo assim, o questionário semiestruturado possibilita que as informações sejam coletadas de forma mais livre e as respostas não estejam condicionadas a uma padronização de alternativas (MANZINI, 1991).

Estruturamos o questionário em três partes. A primeira parte fez uma sondagem sobre os dados de identificação, de formação e de produção do pesquisador (área de atuação, nível de instrução, idade, número de RAGs publicados). A segunda parte, composta de questões com respostas do tipo sim ou não, abordou as impressões do pesquisador em relação ao RAG dentro do seu referido campo acadêmico. A terceira parte do questionário foi composta de questões que visavam inquerir os pesquisadores sobre a função do RAG e sobre o entendimento que possuíam desse gênero quanto ao seu conteúdo proposicional, aspectos formais, público-alvo e trajetória de leitura.

\subsection{ANÁLISE DOCUMENTAL}

Investigamos alguns dos documentos atrelados à produção e ao consumo de RAGs, a fim de coletar maiores informações sobre o contexto em que se inserem. Selecionamos de forma sistemática as Instruções para autores e os Sumários dos periódicos científicos escolhidos para a pesquisa.

\footnotetext{
${ }^{3}$ As entrevistas foram realizadas após a devida aprovação do projeto Uma Análise Crítica de Resumos Acadêmicos Gráficos junto ao Comitê de Ética em Pesquisa (CEP) da UFSM, sob o n 24587813.0 .0000 .5346$.
} 
Quanto às categorias de análise empregadas para a investigação dos dados obtidos por meio das entrevistas e da pesquisa documental, lançamos mão da identificação e sistematização dos marcadores metadiscursivos (VANDE KOPPLE, 1985; CRISMORE; FARNSWORTH, 1989; MORAES, 2005) (Quadro 1) e da interpretação semântica dos elementos utilizados pelo autor do texto ou por aquele que fala para estruturar o conteúdo proposicional de sua mensagem.

Quadro 1: Categorias de análise do modo semiótico verbal a partir de marcadores metadiscursivos

\begin{tabular}{|c|c|c|c|c|c|}
\hline METADISCURSO & \multicolumn{4}{|c|}{ CATEGORIAS } & REALIZAÇÕES \\
\hline \multirow{4}{*}{ TEXTUAL } & \multirow{3}{*}{ Intratextual } & \multirow{2}{*}{$\begin{array}{l}M \\
1 \\
C \\
R \\
O\end{array}$} & $\begin{array}{l}\text { Marcadores } \\
\text { Textuais }\end{array}$ & $\begin{array}{l}\text { Conectivos lógicos } \\
\text { Enumeradores } \\
\text { Anunciadores } \\
\text { Localizadores } \\
\text { Focalizadores }\end{array}$ & $\begin{array}{l}\text { e; mas; consequentemente; portanto; entretanto... } \\
\text { primeiro; segundo; depois; } 1,2 ; \mathrm{a}, \mathrm{b}, \mathrm{c} . . . \\
\text { bem; agora; como veremos a seguir... } \\
\text { acima; abaixo; na Tabela } \mathrm{Y} \text {; como visto... } \\
\text { mais especificamente; especialmente... }\end{array}$ \\
\hline & & & $\begin{array}{l}\text { Marcadores } \\
\text { Informacionais }\end{array}$ & $\begin{array}{l}\text { Topicalizadores } \\
\text { Escl. de conteúdo }\end{array}$ & $\begin{array}{l}\text { quanto a; no que diz respeito a; considerando... } \\
\text { por exemplo; ou seja; isto é... }\end{array}$ \\
\hline & & $\begin{array}{l}M \\
A \\
C \\
R \\
O\end{array}$ & & $\begin{array}{l}\text { Marcadores de ação } \\
\text { Marcadores holísticos } \\
\text { Marcadores ideacionais } \\
\text { Sequenciadores }\end{array}$ & $\begin{array}{l}\text { resumindo; para concluir; minha intenção é... } \\
\text { neste trabalho; neste estudo; nesta pesquisa... } \\
\text { com relação a todas essas questões... } \\
\text { títulos e subtítulos }\end{array}$ \\
\hline & \multicolumn{3}{|l|}{ Intertextual } & $\begin{array}{l}\text { Marcadores de polifonia } \\
\text { Marcadores de contexto }\end{array}$ & $\begin{array}{l}\text { de acordo com X; segundo } Y \ldots \\
\text { em } 2004 ; \text { em } 2013 \ldots\end{array}$ \\
\hline \multirow[t]{3}{*}{ INTERPESSOAL } & \multicolumn{3}{|c|}{ Posicionamento } & $\begin{array}{l}\text { Atenuadores } \\
\text { Enfatizadores } \\
\text { Marcadores de atitude }\end{array}$ & $\begin{array}{l}\text { quase; meramente; só; cerca de; talvez... } \\
\text { completamente; extremamente; muito; obviamente... } \\
\text { curiosamente; felizmente; concordo que... }\end{array}$ \\
\hline & \multicolumn{3}{|l|}{ Diálogo } & Marcadores relacionais & note que; a propósito; observe... \\
\hline & \multicolumn{3}{|l|}{ Presença } & Marcadores de pessoa & eu; meu; nosso; nós... \\
\hline
\end{tabular}

Fonte: Adaptado de Moraes (2005, p. 78).

\section{RESULTADOS}

A análise dos Sumários (Table of Contents), das Instruções para autores dos periódicos científicos selecionados para esta pesquisa e a entrevista com pesquisadores das áreas de Biologia e de Química foi inspirada na perspectiva de observação e averiguação do gênero discursivo com base no seu contexto, conforme proposto por Askehave e Swales (2001), Swales (1998; 2004), Bhatia (2004) e mais recentemente, no contexto nacional, sob a denominação Análise Crítica de Gênero, por Motta-Roth (2006, 2008). Dessa forma, por meio da observação sistemática e análise de marcadores metadiscursivos buscamos identificar: i) o padrão prototípico de leitura de RAGs em termos de passos recorrentes; ii) o padrão prototípico de produção de RAGs em termos de passos recorrentes; iii) a concepção e a familiaridade da comunidade discursiva com os RAGs; e iv) os valores associados ao RAG em termos de função e importância dentro do campo a que pertencem os pesquisadores selecionados para esta pesquisa. De posse dessas informações, que serão detalhadas a seguir, foi possível levantar algumas das características do RAG no que concerne ao seu contexto.

\subsection{SUMÁRIOS (TABLES OF CONTENTS)}

Quanto à investigação dos Sumários dos periódicos científicos, se considerarmos estudos como o de Tenopir et al. (2013) que definem leitura, no âmbito acadêmico, como algo que vai além da leitura de títulos ou resumos e adentra o corpo principal de um artigo, esses Sumários poderiam ser considerados um passo de pré-leitura do artigo acadêmico. Assim, a observação desses quatro Sumários nos auxiliou a compreender o papel que os RAGs ocupam no processo de pré-leitura do artigo acadêmico e se auxiliam (e em que medida) no processo de seleção do artigo acadêmico para a leitura. $\mathrm{Na}$ Imagem 1, apresentamos um exemplo de um desses Sumários. 


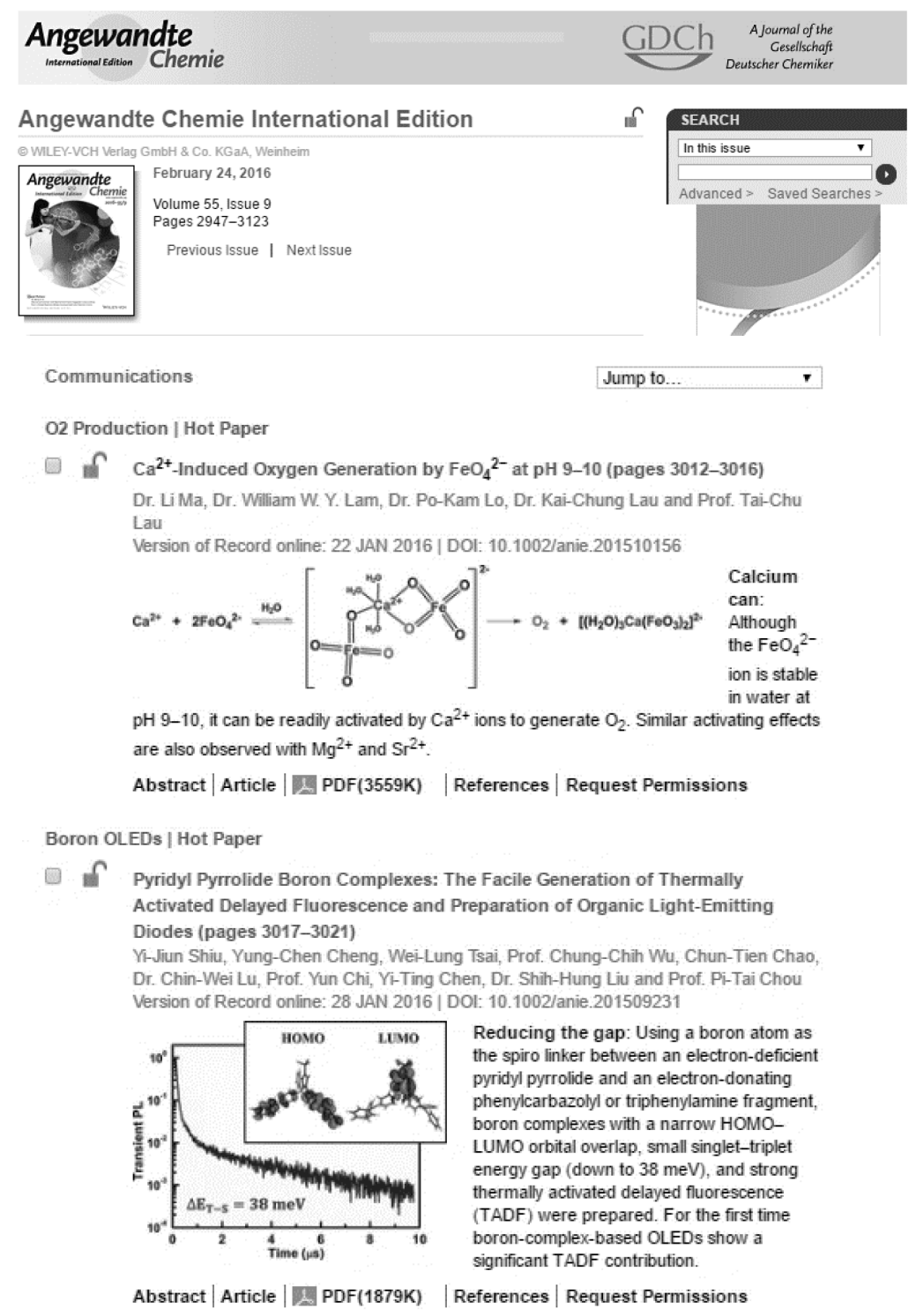

Figura 1: Exemplo de um Sumário de periódico cientítico

Fonte: Angewandte Chemie (2016)

De acordo com o que pudemos observar nos Sumários dos periódicos científicos em questão, eles são um substrato material onde, principalmente, recursos semióticos visuais e verbais se combinam, criando, assim, um espaço multimodal de busca, seleção e préleitura de artigos científicos. Estudos como os de van Leeuwen (1993) e de Kress e van Leeuwen (2006) demonstram que a trajetória de leitura em textos multimodais é orientada pela saliência, seguindo das imagens, ou blocos de texto mais salientes para os menos salientes, por meio de uma seleção das informações mais relevantes (VAN LEEUWEN, 1993). Sendo assim, o leitor, ao deparar-se com um texto multimodal, segundo van Leeuwen (1993), emprega a técnica denominada skimming, ou seja, estabelece conexões entre os diferentes recursos semióticos por meio de relações de importância, normalmente determinada pela relação de contraste e saliência dos elementos apresentados, para efetivar uma estratégia que visa à leitura rápida do texto buscando a sua ideia principal.

Com base na literatura prévia sobre o modo semiótico visual (KRESS; VAN LEEUWEN, 2006) e nas características dos Sumários analisados, observa-se que, do ponto de vista composicional (KRESS; VAN LEEUWEN, 2006), os Sumários apresentam os valores informacionais, principalmente no sentido vertical, de cima para baixo (Nature Chemical Biology; Energy and Environemental Science; Journal of Controled Relesase). Em todas as amostras, o título do artigo acadêmico aparece no topo, seguido do nome dos autores. O RAG aparece logo abaixo do nome dos autores ou, caso as entradas para o texto integral, RA e versão digital do texto integral apareçam logo após o título, abaixo dessas informações. Os elementos verbais restringem-se a palavras isoladas no limite do 
RAG ou a blocos verbais, que aparecem sem regularidade de disposição (acima, abaixo ou ao lado do modo semiótico visual) e são menores ou de mesmo tamanho que o bloco semiótico visual.

A disposição espacial dos Sumários analisados, aliada a outros elementos composicionais como molduragem forte, contraste (em geral, as imagens do RAG são coloridas e o restante do Sumário é preto e branco) e tamanho (em geral, o RAG é o maior bloco de informação do Sumário) colocam o RAG em evidência no Sumários dos periódicos científicos. Assim, considerando que a saliência é um elemento determinante para a definição da trajetória de leitura, podemos notar que a disposição dos modos semióticos (verbal e visual) no Sumário dos períodicos científicos selecionados para esta pesquisa (Figura 1) favorece a leitura do RAG em primeiro lugar. Essas características sugerem que a inserção do RAG no Sumário do periódico científico tenha o propósito de atrair o leitor, conduzindo-o à leitura do artigo científico apresentado.

Leitores/pesquisadores logocêntricos, aqueles que preferem o modo semiótico verbal como fonte de informação, no entanto, podem apresentar alguma resistência e mesmo ignorar o RAG na trajetória de leitura do Sumário e de acesso ao artigo acadêmico, visto que seus padrões culturais de leitura (VAN LEEUWEN, 1993; MARTINEC, 2003; KRESS; VAN LEEUWEN, 2006) remetem a outra trajetória de acesso ao artigo acadêmico. Para esses pesquisadores, habituados à leitura do RA como fonte sucinta das principais descobertas do artigo acadêmico (TENOPIR; KING, 2000; MOTTA-ROTH; HENDGES, 2010), os Sumários dos periódicos científicos (como os selecionados para esta pesquisa) oferecem a possibilidade de clicar de imediato nas entradas $A b s t r a c t$ (Resumo Acadêmico), Full Text (HTML) (Texto Integral em formato digital) ou PDF, que se encontram logo acima ou abaixo do RAG, e acessar o RA do artigo acadêmico ou o artigo acadêmico em sua integralidade.

Contudo, mesmo os leitores mais resistentes já parecem estar incorporando o hábito de ler as imagens do artigo acadêmico antes de ler o RA, em especial nas áreas de Biodiversidade e de Química (conforme dados que serão apresentados na discussão sobre as entrevistas que integram o corpus desta pesquisa). Além disso, especialmente os pesquisadores da área de Ciência da Vida, que engloba a área de Biodiversidade, consideram, segundo Tenopir et al. (2013, p. 46), que as imagens do artigo acadêmico são fontes importantes de informação e meios para a determinação da confiabilidade do artigo acadêmico, tão importantes quanto o RA e os métodos. Assim, de certa forma, o surgimento do RAG não imporia uma nova trajetória de leitura, mas seria uma resposta a uma demanda, um meio de legitimação de uma trajetória ou de uma prática de leitura que já existia.

Os leitores/pesquisadores multimodais, em contrapartida, seriam convidados, pela característica atrativa do RAG, a dar início a uma nova trajetória de leitura, em que a leitura do RAG precederia a do RA, propiciando, assim, a experiência com textos multimodais também no Sumário de periódicos científicos. A coexistência dessas possíveis trajetórias de leitura do Sumário e dessas possíveis formas de acesso ao artigo acadêmico sugere um momento de transição e de sistematização de uma nova forma de entrada em contato com a novidade da pesquisa científica, em que novos hábitos de leitura estão sendo integrados aos antigos, ou hábitos já existentes estão sendo legitimados e/ou consorciados.

Segundo dados de uma densa pesquisa realizada por Tenopir et al. (2013), pesquisadores de áreas afins à área de Biodiversidade veriam, primeiramente no RA e, posteriormente, nas imagens do artigo acadêmico, fontes rápidas para a determinação da confiabilidade da pesquisa e para a seleção do artigo para leitura. Nesse sentido, o RAG comportaria/integraria esses dois passos de leitura em um só, sendo a um só tempo uma imagem importante e um resumo da pesquisa.

Muito embora o acesso aos RAGs não se restrinja à comunidade científica, visto que os Sumários de periódicos científicos são de acesso livre para qualquer usuário que possua uma rede de Internet, o fato de os RAGs serem disponibilizados em Sumários de periódicos científicos sugere que se trata de um texto difundido especialmente no âmbito da comunidade científica. Isso implica o emprego de estratégias e trajetórias de leitura consolidadas dentro dessa comunidade específica e dentro de cada comunidade discursiva em particular. Além disso, algumas ferramentas de busca, como os sistemas de arquivamento online de periódicos científicos (SciElo, Web of Science, ScienceDirect, PubMed, p. ex.), são mais difundidas entre os participantes da comunidade acadêmica do que entre o público em geral (WILLINSKY, 2006). 
Esses sistemas de arquivamento online fornecem resumidamente ao leitor/pesquisador informações dos artigos acadêmicos completos e originais, facilitando a localização do material de interesse, sem que seja necessário procurar minuciosamente todos os periódicos científicos da área em questão. Os periódicos científicos que exigem obrigatoriamente um RAG para a publicação do artigo acadêmico normalmente disponibilizam nos sistemas de arquivamento online o título do artigo acadêmico e o RAG, ou o título, o RAG e logo abaixo o RA ou uma entrada para o RA (Abstract). Sendo assim, o RAG, para os periódicos que o normatizaram, é uma das primeiras informações disponíveis ao leitor nos sistemas de arquivamento online.

Devemos lembrar, no entanto, que ferramentas de busca como Google também são empregadas para a seleção de artigos acadêmicos para a leitura (TENOPIR; KING, 2000; HENDGES, 2007; TENOPIR et al., 2009). Nesses casos, na maioria das vezes, os pesquisadores serão remetidos diretamente para a versão PDF do artigo acadêmico e não terão acesso ao RAG, visto que, em geral, esse resumo não aparece na versão PDF do artigo.

\subsection{INSTRUÇÕES PARA AUTORES}

Os quatro periódicos científicos investigados nesta pesquisa disponibilizam Instruções para autores ou diretrizes para a produção de RAGs e/ou de material gráfico. Por meio do levantamento dos marcadores metadiscursivos das Instruções para autores, encontramos oito tópicos recorrentes sobre a produção de RAGs (Quadro 1): i) Obrigatoriedade; ii) Finalidade; iii) Conteúdo verbal; iv) Conteúdo visual; v) Local de aparição; vi) Aspectos formais; vii) Modo de envio; e viii) Exemplos.

Quadro 2: Tópicos recorrentes nas Instuções para autores de RAGs

\begin{tabular}{|c|c|c|c|c|}
\hline \multirow{2}{*}{ TÓPICOS } & \multicolumn{4}{|c|}{ PERIÓDICOS CIENTÍFICOS } \\
\hline & Nat.Chem.Biol. & Angew.Chem. & J.Control.Release & EnergyEnviron.Sci. \\
\hline Obrigatoriedade & $\begin{array}{l}\text { Resumos gráficos são } \\
\text { publicados com os } \\
\text { seguintes itens }[\ldots]\end{array}$ & $\begin{array}{l}\text { O texto do Sumário deveria } \\
\text { (de preferência com a } \\
\text { ajuda de um gráfico) } \\
\text { despertar a curiosidade. }\end{array}$ & $\begin{array}{l}\text { Os autores devem fornecer } \\
\text { um resumo gráfico }[\ldots] \text {. }\end{array}$ & $\begin{array}{l}\text { Esta entrada deveria incluir } \\
\text { uma imagem colorida [...]. }\end{array}$ \\
\hline $\begin{array}{c}\text { Finalidade do } \\
\text { RAG }\end{array}$ & $\begin{array}{c}{[\ldots] \text { sumarizar o }} \\
\text { manuscrito de uma forma } \\
\text { visual. } \\
{[\ldots] \text { é projetado para atrair a }} \\
\text { atenção dos leitores no } \\
\text { sumário do periódico } \\
\text { científico. }\end{array}$ & {$[\ldots]$ despertar a curiosidade. } & $\begin{array}{c}\text { O resumo deveria } \\
\text { sumarizar os conteúdos } \\
{[\ldots] .} \\
{[\ldots] \text { capturar a atenção de }} \\
\text { um grande número de } \\
\text { leitores... } \\
{[\ldots] \text { ilustrar o tema do }} \\
\text { artigo acadêmico. }\end{array}$ & $\begin{array}{c}{[\ldots] \text { destacar os novos }} \\
\text { aspectos do seu trabalho. }\end{array}$ \\
\hline Conteúdo verbal & $\begin{array}{l}\text { Declarações textuais } \\
\text { devem ser mantidas a um } \\
\text { mínimo. }\end{array}$ & $\begin{array}{l}\text { O texto para o Sumário } \\
\text { deve (de preferência com a } \\
\text { ajuda de um gráfico) }[\ldots] \text {. }\end{array}$ & $\begin{array}{l}\text { Os autores podem também } \\
\text { fornecer um texto } \\
\text { apropriado não superior a } \\
\mathbf{3 0} \text { palavras. }\end{array}$ & \\
\hline Conteúdo visual & $\begin{array}{l}\text { O RAG pode conter } \\
\text { estruturas químicas ou } \\
\text { imagens. } \\
\text { Figuras coloridas são } \\
\text { encorajadas [...]. }\end{array}$ & $\begin{array}{c}\text { [...] o uso de cores é } \\
\text { liberado. } \\
\text { O texto para o Sumário } \\
\text { deve (de preferência com a } \\
\text { ajuda de um gráfico) [...]. }\end{array}$ & & \\
\hline
\end{tabular}




\begin{tabular}{|c|c|c|c|c|}
\hline Local de aparição & $\begin{array}{l}\text { Os RAGs são publicados } \\
\text { com os seguintes } \\
\text { conteúdos: Breve } \\
\text { Comunicação, Artigos, } \\
\text { Resenhas e Perspectivas. } \\
\text { O gráfico [...] será publicado } \\
\text { no Sumário em versão } \\
\text { impressa e online. }\end{array}$ & $\begin{array}{l}\text { O texto para o Sumário } \\
\text { deve (de preferência com a } \\
\text { ajuda de um gráfico) [...]. }\end{array}$ & $\begin{array}{l}\text { O RAG é publicado } \\
\text { somente online. }\end{array}$ & $\begin{array}{c}\text { O resumo gráfico usado no } \\
\text { Sumário do artigo acadêmico } \\
{[\ldots] .}\end{array}$ \\
\hline Aspectos formais & $\begin{array}{c}\text { A imagem deve ser feita sob } \\
\text { medida para caber em um } \\
\text { retângulo de dimensões de } \\
\mathbf{9} \mathrm{cm} \text { de largura por } 4 \mathrm{~cm} \\
\text { de altura. } \\
\text { Todos os resumos gráficos } \\
\text { devem ser apresentados } \\
\text { com um fundo branco e as } \\
\text { imagens devem preencher } \\
\text { a largura disponível, } \\
\text { sempre que possível. }\end{array}$ & & $\begin{array}{l}\text { O conteúdo do RAG deve } \\
\text { ser mantido dentro de uma } \\
\text { área de } 5 \mathbf{c m} \text { a } 17 \mathbf{c m}(\mathbf{1 8 9} \mathbf{x} \\
\mathbf{6 4 2} \text { pixels), as imagens } \\
\text { devem ter resolução } \\
\text { mínima de } 300 \text { dpi e arte de } \\
\text { linha deve estar entre } 1.000 \\
\text { dpi e } 1200 \text { dpi. }\end{array}$ & $\begin{array}{c}\text { Deve incluir uma imagem } \\
\text { colorida, não maior que } 8 \\
\text { cm de largura e } 4 \text { cm de } \\
\text { altura e 20-30 palavras de } \\
\text { texto. } \\
\text { Os gráficos devem ser o mais } \\
\text { claro possível, diagramas } \\
\text { esquemáticos ou reações } \\
\text { simples... }\end{array}$ \\
\hline Modo de envio & $\begin{array}{c}\text { O gráfico deverá ser } \\
\text { apresentado como um } \\
\text { único arquivo usando um } \\
\text { formato de arquivo } \\
\text { padrão... }\end{array}$ & $\begin{array}{c}\text { Para avaliação, favor } \\
\text { integrar figuras ao texto; } \\
\text { após aceitação, entretanto, } \\
\text { serão requeridos arquivos } \\
\text { separados em seu formato } \\
\text { original. }\end{array}$ & $\begin{array}{l}\text { [...] no momento em que o } \\
\text { artigo é submetido. } \\
\text { Os autores devem fornecer } \\
\text { o RAG separadamente } \\
\text { como um arquivo } \\
\text { eletrônico. }\end{array}$ & \\
\hline Exemplos & $\begin{array}{c}\text {...por favor, veja as figuras } \\
\text { do guia para requisitos de } \\
\text { resolução. }\end{array}$ & & $\begin{array}{c}\text { Para exemplos de RAG, } \\
\text { visite a home page do } \\
\text { jornal. }\end{array}$ & $\begin{array}{c}\text { Para exemplos, consulte por } \\
\text { favor a versão online do } \\
\text { periódico. }\end{array}$ \\
\hline
\end{tabular}

Fonte: Elaborado pela autora

De modo geral, as Instruções para autores dos quatro periódicos científicos investigados indicam a Obrigatoriedade de se publicar um resumo gráfico que seja uma imagem colorida ou um gráfico, com a Finalidade de sumarizar visualmente o manuscrito e os conteúdos do artigo, despertar a curiosidade, capturar a atenção e destacar os aspectos inovadores do trabalho. Quanto ao Conteúdo verbal, as Instruções para autores indicam que o uso do modo semiótico verbal deve ser restringido ao mínimo. Quanto ao Conteúdo visual, as Instruções para autores sugerem o uso e/ou salientam a permissão de figuras coloridas, a não obrigatoriedade de a imagem compor o artigo e a permissão do uso de estruturas químicas ou fotografias.

Quanto ao Local de Aparição, as Instruções para autores indicam que os RAGs não são exclusividade de artigos experimentais, podendo aparecer em revisões e artigos teóricos ${ }^{4}$. Além disso, as Instruções para autores salientam que os RAGs podem aparecer na versão impressa e online do periódico científico ou somente na sua versão online, destacando que, normalmente, são publicados no

\footnotetext{
${ }^{4}$ Conforme sistematização apresentada por Macedo e Pagano (2011, p. 265-267) a partir de Swales (2004), o artigo acadêmico pode ser: i) teórico; ii) de revisão; e iii) experimental. O artigo acadêmico teórico propõe ou discute um tema conceitualmente, "[...] trata de assuntos e/ou pesquisas que não envolvem a coleta de dados" (MACEDO; PAGANO, 2011, p. 266). O artigo acadêmico de revisão tem o propósito de analisar sucintamente os progressos recentes em um tema específico a partir da discussão dos resultados apresentados em pesquisas recentes (BERNADINO, 2007). O artigo acadêmico experimental apresenta a descrição da experiência, representa o próprio experimento (BAZERMAN, 1998).
} 
Sumário do artigo acadêmico. No que concerne aos Aspectos formais do RAG, as Instruções para autores oferecem informações sobre: i) o conteúdo representacional (p. ex. estruturas químicas; tema do trabalho; novidades do trabalho); e ii) o conteúdo composional (p. ex. tamanho; disposição espacial; nitidez; e contraste) do RAG.

Em relação ao Modo de Envio do RAG, há Instruções que orientam o envio no ato da submissão e outras que orientam o envio após aceitação do artigo para publicação. Algumas Instruções destacam a necessidade de envio do RAG em arquivo separado do arquivo do artigo acadêmico. Nesse sentido, podemos inferir que as comissões editorias de alguns periódicos científicos, como Angewandte Chemie, possam compreender a importância do RAG especialmente para a busca, seleção e leitura do artigo acadêmico publicado, ao passo que outras possam considerar o RAG um elemento importante também para a seleção do artigo científico para publicação. A maioria das Instruções para autores oferecem Exemplos de RAGs que podem ser consultados nas próprias Instruções ou na versão online do periódico.

A investigação dos tópicos recorrentes das Instruções para autores nos aporta informações gerais relevantes para definições linguísticas iniciais do RAG. Primeiramente, notamos que a existência do RAG tem relação direta com as novas possibilidades de configuração e distribuição de periódicos e artigos científicos, facilitadas pela ascensão de novas tecnologias. Assim, os RAGs aparecem, principalmente, na versão HTML do artigo acadêmico ou se materializam na versão online dos periódicos científicos. Em termos de composição, esse gênero congrega pelo menos o modo semiótico verbal e o visual, com destaque para o primeiro (incentivando o uso de cores, por exemplo) e restrições para o segundo (limitando o uso de elementos verbais). Notamos, também, que em áreas como Biodiversidade e Química e, especialmente, em periódicos científicos de alto Fator de Impacto, os RAGs são obrigatórios, ou sua prática é fortemente sugerida. Com base nas diretrizes específicas quanto à apresentação das informações, principalmente em relação aos significados representacionais e composicionais, podemos inferir que os RAGs possuem a finalidade de sumarizar o tema ou as principais descobertas do artigo acadêmico e capturar a atenção de um largo número de leitores. Possíveis funções adjacentes do RAG, como quanto à sua importância para a seleção de artigos acadêmicos para publicação, ainda não são um consenso. Por fim, com base no teor e detalhamento das Instruções para autores, podemos propor que os RAGs não configuram uma prática corriqueira ou consolidada nas áreas de Química e de Biologia.

\subsection{ENTREVISTAS COM PESQUISADORES DAS ÁREAS DE BIODIVERSIDADE E DE QUÍMICA}

Ainda no que diz respeito à análise contextual, realizamos entrevistas com professore(a)s e estudantes de pós-graduação das áreas de Biodiversidade e de Química. Sete pesquisadore(a)s da área de Biodiversidade (4 pós-doutore(a)s; 2 doutore(a)s e 1 mestrando(a)) e quatro pesquisadore(a)s da área de Química (3 doutore(a)s e 1 mestrando(a)) responderam à entrevista que realizamos. Apresentamos, inicialmente, alguns dados gerais sobre esses pesquisadore(a)s, como idade, especialidade e tempo de atuação na área, número de artigos acadêmicos e de RAGs publicados (Tabela 1) ${ }^{5}$.

De acordo com esses dados, podemos observar que a prática de RAGs é mais recorrente na área de Química, onde 100\% dos pesquisadores entrevistados respondeu já ter produzido RAGs, contra 14\% da área de Biodiversidade. Além disso, de acordo com esses resultados, o número de RAGs publicados pelos pesquisadores da área de Química é bastante expressivo em relação ao número de artigos acadêmicos publicados, chegando a um RAG para cada dois artigos acadêmicos publicados (QD11).

\footnotetext{
${ }^{5}$ No intuito de organizar a análise dos dados coletados nas entrevistas, criamos um código de identificação para cada entrevistado, seguindo os seguintes critérios:

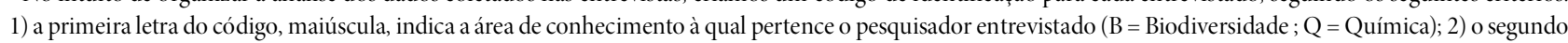
elemento do código indica o maior nível de formação do entrevistado. Assim, a letra M indica Mestrado; a letra D indica Doutorado e a combinação Pd indica PósDoutorado; 3) o terceiro elemento do código é um sinal de \#, lido como número; e 4) o quarto elemento do código indica, em ordem crescente, o número da entrevista. De 1 a 4, estão compreendidos os pesquisadores da área de Biodiversidade e de 5 a 11, os pesquisadores da área de Química.
} 


\begin{tabular}{|c|c|c|c|c|c|}
\hline \multirow[b]{2}{*}{ CÓDIGO } & \multicolumn{5}{|c|}{ BIODIVERSIDADE } \\
\hline & Idade & Especialidade & $\begin{array}{l}\text { Tempo de } \\
\text { atuação em } \\
\text { pesquisa na } \\
\text { área }\end{array}$ & $\begin{array}{l}\text { No de artigos } \\
\text { publicados }\end{array}$ & $\begin{array}{l}\text { No de RAGs } \\
\text { publicados }\end{array}$ \\
\hline $\mathrm{BM} \# \mathbf{1}$ & 28 anos & Biologia Molecular & 3 anos & 2 & Nenhum \\
\hline $\mathrm{BD} \# 2$ & 53 anos & Biologia Molecular & 30 anos & 105 & Nenhum \\
\hline $\mathrm{BD} \# 3$ & 49 anos & Biologia Molecular & 29 anos & +ou- 80 & Nenhum \\
\hline $\mathrm{BPd} \# 4$ & 43 anos & Ecologia de Mamíferos & 17 anos & 73 & Nenhum \\
\hline $\mathrm{BPd} \# 5$ & 52 anos & $\begin{array}{c}\text { Fisiologia e Farmacologia de } \\
\text { Peixes }\end{array}$ & 30 anos & 172 & Nenhum \\
\hline BPd $\# 6$ & 32 anos & Biologia Molecular & 9 anos & 12 & 4 \\
\hline BPd\#7 & 27 anos & Biologia Molecular & 10 anos & 10 & Nenhum \\
\hline
\end{tabular}

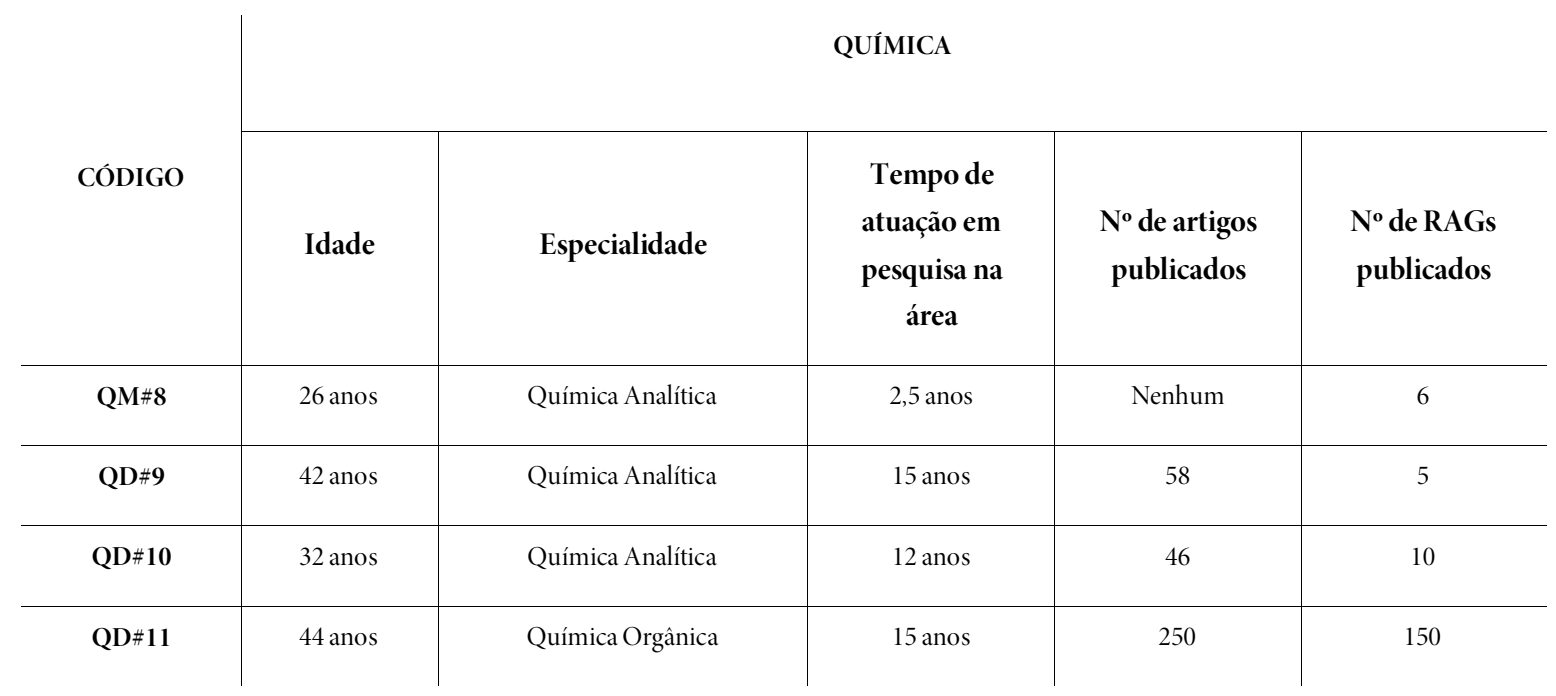

Tabela 1: Dados gerais sobre os pesquisadores entrevistados

Fonte: Elaborado pela autora

Com relação às questões da entrevista cujas respostas poderiam ser do tipo sim ou não, nossos dados (Tabela 2) revelam que a maioria dos pesquisadores (90\%) sabe o que é um RAG e 64\% deles acredita que publicações que apresentam RAGs são frequentes. Imagens em geral, e RAGs em especial, segundo 90\% dos entrevistados, atraem a atenção do leitor. $90 \%$ dos entrevistados afirmou ler os RAGs quando os encontra em alguma publicação científica. 63\% acredita que o RAG auxilia o pesquisador na seleção de artigos acadêmicos para leitura e 64\% acredita que os RAGs auxiliam também os editores de periódicos científicos a avaliarem artigos acadêmicos para publicação. No entanto, a maioria dos pesquisadores ouvidos (73\%) diz não acreditar que o RAG possa vir a substituir o resumo acadêmico. 
De acordo com 64\% dos entrevistados, os pesquisadores iniciantes não estão preparados para ler ou produzir um RAG. Quanto aos leitores não especialistas, $56 \%$ dos entrevistados acredita que o uso de RAGs em artigos científicos não os atrai para a leitura do artigo científico, enquanto 45\% dos entrevistados acredita que os não-especialistas podem ser atraídos para a leitura do artigo científico por meio do RAG.

\begin{tabular}{|c|c|c|c|c|c|c|}
\hline \multirow{2}{*}{ QUESTÃO } & \multicolumn{2}{|c|}{ BIODIVERSIDADE } & \multicolumn{2}{|c|}{ QUÍMICA } & \multicolumn{2}{|c|}{ TOTAL } \\
\hline & SIM & NÃO & SIM & NÃO & SIM & NÃO \\
\hline $\begin{array}{l}\text { Você sabe o que é um Graphical Abstract (Resumo } \\
\text { Acadêmico Gráfico - RAG)? }\end{array}$ & $86 \%$ & $14 \%$ & $100 \%$ & $0 \%$ & $90 \%$ & $10 \%$ \\
\hline $\begin{array}{c}\text { Na sua experiência/opinião, publicações que } \\
\text { apresentam RAGs são frequentes? }\end{array}$ & $29 \%$ & $71 \%$ & $50 \%$ & $50 \%$ & $36 \%$ & $64 \%$ \\
\hline $\begin{array}{l}\text { Quando você acessa uma publicação online que } \\
\text { apresenta RAGs, você costuma lê-los? }\end{array}$ & $100 \%$ & $0 \%$ & $75 \%$ & $25 \%$ & $90 \%$ & $10 \%$ \\
\hline Você já produziu/escreveu um RAG? & $43 \%$ & $57 \%$ & $75 \%$ & $25 \%$ & $55 \%$ & $45 \%$ \\
\hline $\begin{array}{c}\text { Você acredita que os RAGs auxiliam o pesquisador } \\
\text { a selecionar artigos científicos para a leitura? }\end{array}$ & $71 \%$ & $29 \%$ & $75 \%$ & $25 \%$ & $73 \%$ & $27 \%$ \\
\hline $\begin{array}{l}\text { Você acredita que os RAGs auxiliam os editores e } \\
\text { avaliadores de periódicos científicos a selecionarem } \\
\text { artigos científicos para publicação? }\end{array}$ & $57 \%$ & $43 \%$ & $75 \%$ & $25 \%$ & $64 \%$ & $36 \%$ \\
\hline $\begin{array}{c}\text { Pela sua experiência, você considera que os RAGs } \\
\text { poderiam substituir o Resumo Acadêmico } \\
\text { (verbal/escrito)? }\end{array}$ & $29 \%$ & $71 \%$ & $25 \%$ & $75 \%$ & $27 \%$ & $73 \%$ \\
\hline $\begin{array}{l}\text { Você acredita que pesquisadores iniciantes (p. ex. } \\
\text { alunos de pós-graduação) estão preparados para ler } \\
\text { e/ou produzir um RAG? }\end{array}$ & $29 \%$ & $71 \%$ & $50 \%$ & $50 \%$ & $36 \%$ & $64 \%$ \\
\hline $\begin{array}{l}\text { Você acredita que o uso de imagens em geral, e } \\
\text { RAGs em particular, em artigos científicos atrai o } \\
\text { cientista? }\end{array}$ & $100 \%$ & $0 \%$ & $75 \%$ & $25 \%$ & $90 \%$ & $10 \%$ \\
\hline $\begin{array}{l}\text { Você acredita que o uso de RAGs em artigos } \\
\text { científicos atrai o leitor não especialista - público } \\
\text { em geral da Internet? }\end{array}$ & $43 \%$ & $57 \%$ & $50 \%$ & $50 \%$ & $45 \%$ & $56 \%$ \\
\hline
\end{tabular}

Tabela 2: Resultados das questões objetivas sobre RAGs aplicadas a pesquisadores da área de Biodiversidade e de Química Fonte: Elaborado pela autora

Quanto às questões da segunda parte das entrevistas, as respostas obtidas (Quadro 2) sobre os RAGs podem ser organizadas em termos de: i) conceito; ii) função; iii) conteúdo; iv) aspectos formais; v) público-alvo; e vi) trajetória de leitura. 
Quadro 3: Tópicos sobre o RAG destacados pelos pesquisadores entrevistados

\begin{tabular}{|c|c|c|}
\hline O RAG & BIODIVERSIDADE & QUÍMICA \\
\hline Conceito & $\begin{array}{l}\text { - Imagem que resume a ideia principal do trabalho e os principais } \\
\qquad \text { resultados (BM1); } \\
\text { Linguagem nova, atraente (BD2); } \\
\text { - Imagem prática que oferece um panorama geral do trabalho } \\
\qquad \text { (BD3); } \\
\text { - Resumos dos principais passos do trabalho (BPd4); } \\
\text { - Forma gráfica de fácil compreensão e rápida visualização } \\
\text { (BPd5); } \\
\text { - Imagem simples acompanhada de resumo simples das } \\
\text { principais descobertas / conclusões do artigo (BPd6); } \\
\text { - Forma gráfica de expressar as principais conclusões/descobertas } \\
\text { (BPd7). }\end{array}$ & $\begin{array}{l}\text { - Esquema do trabalho desenvolvido, no qual estão } \\
\text { apontados os principais etapas do trabalho } \\
\text { experimental (QM8); } \\
\text { - Ferramenta didática que oferece a informação } \\
\text { destaque do artigo (QD9); } \\
\text { - O RAG é meramente ilustrativo e não traz } \\
\text { informações detalhadas sobre o assunto do artigo. } \\
\text { (QD10); } \\
\text { - O RAG é uma ferramenta que pode ser utilizada para } \\
\text { capturar a atenção e o interesse do leitor (QD11). }\end{array}$ \\
\hline Função & $\begin{array}{l}\text { - Atrair a atenção do público com vistas à citações (BM1); } \\
\text { - Sintetizar informações de relações, interações e processos da } \\
\text { pesquisa (BD2); } \\
\text { - Dar um panorama geral do trabalho desenvolvido (BD3); } \\
\text { - Otimizar o tempo de seleção de artigos para leitura, embora a } \\
\text { função possa variar de acordo com a área e com as suas } \\
\text { necessidades (BPh4); } \\
\text { - Mostrar os resultados do trabalho publicado (BPd5); } \\
\text { - Capturar, de forma imediata e eficiente, o olhar dos leitores } \\
\text { para o conteúdo do artigo (BPh6); } \\
\text { - Contextualizar o tema, apresentando alguns resultados e, assim, } \\
\text { otimizando o tempo de seleção do artigo (BPd7) }\end{array}$ & $\begin{array}{l}\text { - Auxiliar no momento da seleção do artigo para } \\
\qquad \text { leitura (QM8); } \\
\text { - Ressaltar alguma informação que merece atenção } \\
\text { especial no artigo a fim de auxiliar a leitura (QD9); } \\
\text { - Ilustrar o artigo acadêmico (QD10); } \\
\text { - Capturar a atenção e o interesse do leitor (QD11). }\end{array}$ \\
\hline Conteúdo & $\begin{array}{l}\text { - Forma reduzida dos objetivos e hipóteses, introdução, métodos } \\
\qquad \text { e resultados (BM1); } \\
\text { - Conceitos ou elementos principais, relações entre os conceitos e } \\
\text { produtos finais do processo de pesquisa (BD2); } \\
\text { - Objeto central da pesquisa e passos que levaram ao resultado } \\
\qquad \text { (BD3); } \\
\text { - Reprodução do método científico empregado para se chegar } \\
\text { aos resultados: lançar o problema; fazer predições sobre o } \\
\text { assunto; apresentar a metodologia, os principais resultados e as } \\
\text { conclusões) (BPd4); } \\
\text { - Esquema de resultados e conclusões do artigo (BPd5); } \\
\text { - Principais resultados e conclusões do artigo (BPd6); }\end{array}$ & $\begin{array}{l}\text { - Objetivos, metodologia, resultados mais } \\
\text { significativos (QM8); } \\
\text { - Depende do apelo do artigo (QD9); } \\
\text { - Focado nas palavras-chave do trabalho e nos } \\
\text { objetivos (QD10); } \\
\text { - Informações centrais do artigo como objetivos, } \\
\text { resultados e conclusões (QD11). }\end{array}$ \\
\hline
\end{tabular}




\begin{tabular}{|c|c|c|}
\hline & $\begin{array}{l}\text { - Pontos mais importantes do trabalho: hipóteses, métodos e } \\
\text { resultados }(\mathrm{BPd} 7) .\end{array}$ & \\
\hline $\begin{array}{l}\text { Aspectos } \\
\text { Formais }\end{array}$ & $\begin{array}{l}\text { - Apresentação de imagens com boa resolução e corretas (BM1); } \\
\text { - Distribuir no espaço os elementos de forma a representar com } \\
\text { setas as relações entre eles e nas setas finais os produtos ou } \\
\text { conclusões (BD2); } \\
\text { - Clareza (BPd4); } \\
\text { - Clareza, concisão (BPd6); } \\
\text { - Um fluxograma seria uma das formas mais interessantes para } \\
\text { resumir os pontos principais do trabalho (BPd7). }\end{array}$ & $\begin{array}{l}\text { - Apresentação clara e simples das informações mais } \\
\text { significativas do trabalho (QM8); } \\
\text { - Clareza e objetividade (QD9); } \\
\text { - O RAG deve ser autoexplicativo, com fonte maior } \\
\text { possível e legível, não poluído visualmente (QD10); } \\
\text { - Clareza e objetividade (QD11). }\end{array}$ \\
\hline Público Alvo & $\begin{array}{l}\text { - Profissionais da área, principalmente, e eventuais profissionais } \\
\qquad \text { de outras áreas (BM1); } \\
\text { - Profissionais da área (BPd4); } \\
\text { - Público leigo na área do conhecimento em questão, mas com } \\
\text { interesse no assunto abordado no artigo (BPd6); } \\
\text { - Pesquisadores que não trabalham na mesma área dos autores } \\
\text { do artigo publicado, para que consigam entender a principal } \\
\text { mensagem do RAG apenas por meio do RAG (BPd7). }\end{array}$ & $\begin{array}{l}\text { - Especialistas da área de estudo do trabalho (QM8); } \\
\text { - Especialistas da área de estudo do trabalho (QD9); } \\
\text { - Especialistas da área de estudo do trabalho (QD10); } \\
\text { - Público da área que acompanha a literatura da área } \\
\text { (QD11). }\end{array}$ \\
\hline $\begin{array}{l}\text { Trajetória de } \\
\text { Leitura }\end{array}$ & $\begin{array}{l}\text { - Observar a figura em busca de um ponto principal de atenção e } \\
\text { a partir desse ponto relacionar os elementos representados (caso } \\
\text { não encontre esse elemento principal, desiste da leitura); } \\
\text { - Identificar os componentes principais, observar como os } \\
\text { elementos estão relacionados e os processos que essas relações } \\
\text { representam (se houver), observar quais são os } \\
\text { produtos/conclusões (BD2); } \\
\text { Situar um ponto inicial à esquerda e prosseguir para a direta ou } \\
\text { ao centro e observar o entorno (BPd4); } \\
\text { - Seguir as setas, caso houver; se não, observar a globalidade da } \\
\text { imagem e posteriormente observar os detalhes. (BPd5); } \\
\text { - Ler primeiramente o modo semiótico verbal e após o visual da } \\
\text { imagem (BPd6); }\end{array}$ & $\begin{array}{l}\text { - Observar e seguir as setas da imagem; se não houver } \\
\text { setas, seguir o padrão de leitura esquerda/direita; } \\
\text { - Do título para o RAG (QD9); } \\
\text { - Da esquerda para a direita ou do centro para as } \\
\text { margens (QD10); } \\
\text { - Analisar as informações que estão em evidência, pois } \\
\text { podem conter a ideia principal do artigo (QD11). }\end{array}$ \\
\hline
\end{tabular}

Fonte: Elaborado pela autora

Observamos que não existe consenso sobre o melhor termo para definir o RAG entre os pesquisadores das áreas de Biodiversidade e de Química. De maneira geral, o RAG é definido como imagem, linguagem, resumo, forma gráfica, ferramenta, ilustração ou esquema "simples e conciso sobre as principais conclusões ou descobertas do artigo" (BPd6), onde estão apontadas "as principais etapas do trabalho experimental” (QM8). 
A função do RAG, segundo os pesquisadores é “capturar, de forma imediata e eficiente, o olhar dos leitores para o conteúdo do artigo" (BPd6) e otimizar o tempo de busca por artigos acadêmicos para leitura.

Em termos de conteúdo proposicional, em geral os pesquisadores entrevistados acreditam que o RAG deveria representar o objeto principal da pesquisa e as etapas que levaram aos resultados e conclusões obtidos. Notamos que o uso de setas é sugerido como forma de representar e ordenar a progressão das etapas (BD2; BPd4; BPd5; BPd7; QD8).

Em relação aos aspectos formais do RAG, os entrevistados demonstraram preocupação com a apresentação clara, concisa, nítida, organizada e lógica. Assim como o pesquisador BPd7, a maior parte dos pesquisadores afirmaram que quando escreveram/escreveriam um RAG priorizaram/priorizariam "pontos mais importantes do trabalho que possam/[pudessem] ser representados em figuras esquemáticas de fácil interpretação”. Observamos que, assim como o pesquisador QD10, os demais pesquisadores primam por um RAG "autoexplicativo".

Não há consenso entre os pesquisadores sobre o público-alvo dos RAGs. De modo geral, a ênfase é dada a pesquisadores da área e "eventuais profissionais de outras áreas" (BM1). O pesquisador BPd4 faz uma observação em que compara as áreas de Química e de Bioversidade, sobretudo sua Especialidade, Ecologia de Mamíferos. Segundo esse pesquisador, algumas Especialidades da Área de Biodiversidade são mais “próximais” à experiência dos leitores, sejam eles especialistas ou não. Logo, de acordo com o entrevistado BPd4, o RAG não se faria tão necessário na área de Biodiversidade quanto na de Química, onde, em geral, os objetos de estudo são menos relacionáveis à experiência. Assim, de acordo com esse pesquisador, a prática de RAGs na Química se justificaria melhor do que na área de Biodiversidade, mas, mesmo assim, seria restrita à leitura de "especialistas da área ou de áreas afins”.

O percurso de leitura que os entrevistados afirmaram realizar ao ler um RAG revela que, inicialmente, a imagem é observada por esses pesquisadores em busca de um "ponto principal de atenção" (BM1). A partir desse ponto principal, os pesquisadores buscam "observar como os elementos estão relacionados e os processos que essas relações representam (se houver)" (BD2). Alguns pesquisadores (BPd4; QM8) responderam que seguem as setas da imagem e, caso não existam setas, buscam se guiar pelo padrão de leitura ocidental (KRESS; VAN LEEUWEN, 2006): esquerda - direita; superior - inferior.

A análise documental realizada nos Sumários dos periódicos científicos e nas Instruções para autores de RAGs e as entrevistas realizadas com profissionais das áreas de Biodiversidade e de Química foram importantes para elucidar questões sobre o contexto de produção e de consumo de RAGs. Assim, podemos inferir que, de acordo com: i) os Sumários dos periódicos científicos: os RAGs aparecem em destaque, apresentando uma natureza publicitária, que busca atrair a atenção do leitor; ii) as Intruções para autores: os RAGs possuem materialidade e função que busca sumarizar o tema e as principais descobertas da pesquisa científica, oferecendo pistas sobre a realização retórica do RAG; e iii) as entrevistas: os RAGs têm a função de atrair o leitor; não substituem o RA; apresentam as principais conclusões e descobertas do artigo acadêmico e as etapas mais relevantes da pesquisa científica.

Os resultados revelam especialmente que o RAG se diferenciam do RA em termos de função. Isso significa que o(s) propósito(s) comunicativo(s) desses dois gêneros são diferentes, pelo menos em termos de propósito comunicativo principal. Segundo a literatura prévia (MOTTAROTH; HENDGES, 2010, p. 152), o propósito comunicativo principal do RA é "[...] indicar e predizer, em um parágrafo curto, o conteúdo e a estrutura do texto integral que segue”. O propósito comunicativo principal do RAG, segundo nossa investigação, é atrair a atenção do leitor, sumarizando de forma bastante persuasiva, por meio de recursos verbo-visuais, com ênfase para o visual, duas etapas consideradas essenciais na pesquisa, a metodologia empregada e os resultados obtidos.

\section{CONSIDERAÇÕES FINAIS}

Como explanamos ao longo deste artigo, a ACG, base teórico-metodológica empregada em nossa pesquisa, preconiza que o estudo de um gênero discursivo requer investigação textual e contextual. Por questões de sistematização e de espaço, apresentamos neste artigo apenas os resultados da análise contextual realizada em periódicos científicos e documentos atrelados à produção de RAGs nas áreas de Biodiversidade e de Química. 
Ainda em termos metodológicos, é importante destacar que os resultados deste estudo provêm de um enfoque limitado em relação ao complexo universo das publicações científicas (WARE, 2012). Grandes Áreas, como Ciências Sociais Aplicadas, Ciências Humanas, Linguística, Letras e Artes (CAPES, 2014), não apresentam produção recorrente de RAGs como as áreas de Química e de Biodiversidade, impossibilitando uma comparação entre áreas do conhecimento de diferentes naturezas.

Essa limitação, no entanto, aporta um importante resultado sobre o contexto dos RAGs, demonstrando que a prevalência de RAGs em determinadas áreas do conhecimento pode ser consequência de uma demanda histórica (NATURE, 2011) impulsionada pelas características específicas do objeto de estudo de certas áreas, o que conduz à preferência pela apresentação dos resultados da pesquisa por meio de uma imagem sintética, legível pelos demais pesquisadores do campo em função dos conhecimentos específicos que compartilham sobre os códigos visuais da área, como inclusive nos alerta um dos pesquisadores entrevistados para este estudo.

A investigação do contexto de produção e de leitura de RAGs revela um padrão de produção que busca atrair a atenção dos leitores e, em certa medida, instalar uma trajetória nova/alternativa de leitura das principais descobertas do artigo acadêmico. Contudo, é importante salientar que o RAG coexiste com o RA e, pelo o que nossos dados indicam, no contexto científico atual, não se dispensa a existência deste último. A prática de RAGs demostra também que o ambiente online de periódicos científicos é um espaço dinâmico que possibilita o emprego da multimodalidade na difusão de pesquisas científicas. Desse modo, o RAG pode ser uma resposta/adaptação aos avanços e mudanças do contexto científico, o qual tem cada vez mais lançado mão do modo semiótico visual para representar suas práticas. Além disso, o RAG pode ser uma resposta à necessidade de otimização do tempo de busca e de seleção de artigos acadêmicos para leitura e de aprimoramento dos meios de divulgação das descobertas científicas no âmbito do ciclo das publicações científicas ${ }^{6}$.

\section{REFERÊNCIAS}

ANGEWANDTE CHIMIE. Table of Contents. v. 55, n. 9. Disponível em: < http://onlinelibrary.wiley.com/doi/10.1002/anie.v55.9/issuetoc $>$. Acesso em: 06 set. 2016.

ASKEHAVE, I.; SWALES, J. M. Genre identification and communicative purpose: a problem and a possible solution. Applied Linguistics, v. 22, n. 2, p. 195-212, 2001. Disponível em: <http://applij.oxfordjournals.org/content/22/2/195.full.pdf+html >. Acesso em: 07 set. 2016.

AYERS, G. The evolutionary nature of genre: an investigation of the short texts accompanying research articles in the scientific journal Nature. English for Specific Purposes, v. 27, p. 22-41, 2008. Disponível em:

< http://www.sciencedirect.com/science/article/pii/S0889490607000221>. Acesso em: 06 set. 2016.

BAKHTIN, M. M. Speech genres and other late essays. Austin: University of Texas Press, 1986.

. Problemas da poética de Dostoiévski. Rio de Janeiro: Forense Universitária, 2008.

. Os gêneros do discurso. In: BAKHTIN. M. Estética da criação verbal. São Paulo: Martins Fontes, 2011. p. 261-335.

BAWARSHI, A. S.; REIFF, M. J. Gênero: história, teoria, pesquisa e ensino. São Paulo: Parábola, 2013.

${ }^{6}$ No intuito de exercitar e exemplifiar a prática estudada e discutida neste artigo, apresentamos no ANEXO A um RAG referente à pesquisa que aqui apresentamos. 
BAZERMAN, C. Modern evolution of experimental report in Physics: spectroscopic articles in Physical Review, 1893-1980. Social Studies of Science, v. 14, n. 2, p. 163-196, 1984. Disponível em: < http://sss.sagepub.com/content/14/2/163.full.pdf+html>. Acesso em: 07 set. 2016.

Shaping written knowledge: the genre and activity of the experimental article in science. Madison: University of Wisconsin Press, 1988.

BERNARDINO, C. G. O metadiscurso interpessoal em artigos acadêmicos: espaço de negociações e construção de posicionamentos. 2007. 243f. Tese (Doutorado em Linguística Aplicada) - Universidade Federal de Minas Gerais, Belo Horizonte, 2007.

BHATIA, V. K. Analyzing genre: language use in professional settings. London, Longman, 1993.

Worlds of written discourse: a genre-based view. London: Continuum, 2004.

CRISMORE, A.; FRANSWORTH, R. Mr. Darwin and his readers: exploring interpersonal metadiscourse as a dimension of Ethos. Rhetoric review, v. 8, n. 1, p. 91-112, 1989. Disponível em: < http://www.jstor.org/stable/465683?seq=1\#fndtnpage_scan_tab_contents>. Acesso em: 07 set. 2016.

ELSEVIER B. V. Article of the future. 2009. Disponível em: <http://www.elsevier.com/about/mission/innovative-tools/article-ofthe-future>. Acesso em: 18 jul. 2013.

For authors: graphical abstracts. 2014. Disponível em: <http://www.elsevier.com/journal-authors/graphical-abstract>. Acesso em: 23 jun. 2014.

FAIRCLOUGH, N. Analysing discourse: textual analysis for social research. London and New York: Routledge, 2003.

Discourse and social change. Cambridge: Polity Press, 1992.

Language and power. London: Longman, 1989.

FEMS. Graphical abstract and one-sentence summary. 2014. Disponível em: <http://www.femsmicrobiology.org/journals/graphical-abstract.html>. Acesso em: 23 jun. 2014.

FLOREK, C. S. Uma análise crítica de gênero de resumos acadêmicos gráficos. 2015. 240 f. Dissertação (Mestrado em Letras) Universidade Federal de Santa Maria, Santa Maria, 2015.

FLOREK, C.; HENDGES, G. R. Resumos acadêmicos gráficos: categorias e graus de especialização. Expressão, Santa Maria, v. 17, n. 2, p. 105-112, 2013.

GOLEBIOWSKI, Z. Prominent messages in education and applied linguistic abstracts: how do authors appeal to their prospective readers? Journal of Pragmatics, n. 41, p. 753-769, 2009. Disponível em: < http://www.sciencedirect.com/science/article/pii/S0378216608002725>. Acesso em: 07 set. 2016.

HALLIDAY, M. A. K. An introduction to functional grammar. London: Edward Arnold, 1994.

HALLIDAY, M. A. K.; HASAN, R. Language, context, and text: aspects of language in a social-semiotic perspective. Oxford: Oxford University Press, 1985, 1989.

HALLIDAY, M. A. K.; MATTHIESSEN, C. M. I. M. An introduction to functional grammar. London: Edward Arnold, 2004. 
HENDGES, G. R. Tackling genre classification: the case of HTML research articles. 2007. 209 f. Tese (Doutorado em Linguística Aplicada) - Universidade Federal de Santa Catarina, Florianópolis, 2007.

KRESS, G. Multimodality: a social semiotic approach to contemporary communication. New York, Routledge, 2010.

KRESS, G.; VAN LEEUWEN, T. Reading images: the grammar of visual design. New York, Routledge, 1996.

KRESS, G.; VAN LEEUWEN, T. Reading images: the grammar of visual design. London: Routledge, 2006.

LORÉS, R. On RA abstracts: from rhetorical structure to thematic organization. English for specific purposes, v. 23, p. 280-302, 2004.

MACEDO, T.; PAGANO, A. S. Análise de citações em textos acadêmicos escritos. DELTA, São Paulo, v. 27, n. 2, p. 257-288, 2011.

MANZINI, E. J. A entrevista na pesquisa social. Didática, v. 26/27, p. 149-158, 1991.

MARTIN, J. R. English text: system and structure. Amsterdam: John Benjamins, 1992.

Mentoring semogenesis: 'genre based' literacy pedagogy. In: CHRISTIE, F. (Ed.). Pedagogy and shaping of consciousness: linguistics and social processes. London and New York: Continuum, 1999. p. 123-55.

MARTIN, J. R.; ROSE, D. Working with discourse: meaning beyond the clause. London and New York: Continuum, 2003.

MARTINEC, R. The social semiotics of text and image in [j]apanese and [e]nglish software manuals and other procedures. Social semiotics, v. 13, n. 1, p. 43-69, 2003. Disponível em: < http://www.tandfonline.com/doi/abs/10.1080/1035033032000133878>. Acesso em: 07 set. 2016.

MEURER, J. L. Gêneros textuais na Análise Crítica de Fairclough. In: MEURER, J. L.; BONINI, A.; MOTTA-ROTH, D. (Org.). Gêneros: teorias, métodos, debates. São Paulo: Parábola Editorial, 2005. p. 81-106. Uma dimensão crítica do estudo de gêneros textuais. In: MEURER, J. L.; MOTTA-ROTH, D. (Org.). Gêneros textuais e práticas discursivas: subsídios para o ensino da linguagem. Bauru: EDUSC, 2002. p. 17-29.

.; MOTTA-ROTH, D. (Org.). Parâmetros de textualização. Santa Maria: Ed. da UFSM, 1997.

MILLER, C. Genre as social action. Quarterly journal of speech, v. 70, p. 157-78, 1984. Disponível em: $<$ http://www.tandfonline.com/doi/abs/10.1080/00335638409383686>. Acesso em 07 set. 2016.

MORAES, L. S. B. O metadiscurso em artigos acadêmicos: variação intercultural, interdisciplinar e retórica. 2005. 194f. Tese (Doutorado em Letras) - Pontifícia Universidade Católica do Rio de Janeiro, Rio de Janeiro-RJ, 2005.

MOTTA-ROTH, D. Analise crítica de gêneros: contribuições para o ensino e a pesquisa de linguagem. DELTA, São Paulo, v. 24, p. 341-383, 2008.

Questões de metodologia em análise de gêneros. In: KARWOSKI, A. M.; GAYADECKA, B.; BRITO, K. S. (Org.). Gêneros textuais: reflexões e ensino. 2 ed. Rio de Janeiro: Lucerna, 2006. p. 145-163.

.; HENDGES, G. R. Produção textual na universidade. São Paulo: Parábola Editorial, 2010.

.; HENDGES, G. R. Uma análise de gênero de resumos acadêmicos (abstracts) em Economia, Linguística e Química. Revista do Centro de Artes e Letras, Santa Maria, n. 18, p. 53-90, 1996. 
MOTTA-ROTH, D.; MARCUZZO, P. Ciência na mídia: análise crítica de gênero de notícias de popularização científica. Revista brasileira de Linguística Aplicada, Belo Horizonte, v. 10, n. 3, p. 511-538, 2010.

NATURE. The art of abstracts, v. 3, Aug. 2011. Disponível em: <www.nature.com/naturechemistry>. Acesso em: maio 2012.

NATURE. How to submit. Graphical abstract. 2014 Disponível em: <http://www.nature.com/nchem/authors/submit.html\#Graphical-abs>. Acesso em: 23 jun. 2014.

NEW LONDON GROUP. A pedagogy of multiliteracies: designing social futures. Harvard Educational Review, v. 1, n. 66, p. 60-92, 1996. Disponível em: < http://hepgjournals.org/doi/abs/10.17763/haer.66.1.17370n67v22j160u>. Acesso em: 07 set. 2016.

O’TOOLE, M. The language of displayed art. Leicester: Leicester University Press, 1994.

O'HALLORAN, K. L. Introduction. In: O'HALLORAN, K. L (Ed.). Multimodal discourse analysis: systemic functional perspectives. London and New York: Continuum, 2004. p. 1-7.

PALTRIDGE, B. Textographies and the researching and teaching of writing. Ibérica, v. 14, p. 9-24, 2008. Disponível em: < http://www.aelfe.org/documents/02_15_Paltridge.pdf>. Acesso em: 07 set. 2016.

SAMRAJ, B. An exploration of a genre set: research article abstracts and introductions in two disciplines. English for specific purposes, v. 24, n. 2, p. 141-156, 2005. Disponível em: < http://www.sciencedirect.com/science/article/pii/S088949060300067X>. Acesso em: 07 set. 2016.

SWALES, J. M. Genre analysis: English in academic and research settings. Cambridge Univesity Press, 1990.

SWALES, J. M. Other floors, other voices: a textography of a small university building. New Jersey: Lawrence Erlbaum, 1998.

SWALES, J. M. Research genres: explorations and applications. New York: Cambridge University Press, 2004.

TENOPIR, C. et al. Trust and authority in scholarly communications in the light of digital transition: final report. USA and UK: University of Tennessee USA and CIBER Research Ltd UK, 2013.

TENOPIR, C.; KING, D. W. Towards electronic journals: realities for scientists, librarians and publishers. Washington: Special Libraries Association, 2000.

VAN LEEUWEN, T. Genre and field in critical discourse analysis. Discourse \& society, v. 4, n. 2, p. 193-223, 1993. Disponível em: < http://das.sagepub.com/content/4/2/193.full.pdf+html>. Acesso em: 07 set. 2016.

VAN LEEUWEN, T. Introducing social semiotics. London and New York: Routledge, 2005.

VANDLE KOPPLE, W. J. Some exploratory discourse on metadiscourse. College composition and communication, v. 36. n. 1, p. 8283, 1985. Disponível em: < https://www.jstor.org/stable/357609?seq=1\#page_scan_tab_contents>. Acesso em: 07 set. 2016.

WARE, M. An overview of scientific and scholarly journal publishing. Oxford: Technical and Medical Publishers, 2012.

WODAK, R.; MEYER, M. (Ed.). Methods for critical discourse analysis. London: Sage, 2009.

WILLINSKY, J. The access principle: the case for open access to research and scholarship. England: The MIT Press, 2006. 
ANÁLISE CONTEXTUAL DE RESUMOS ACADÊMICOS GRÁFICOS DE BIOLOGIA E DE QUÍMICA
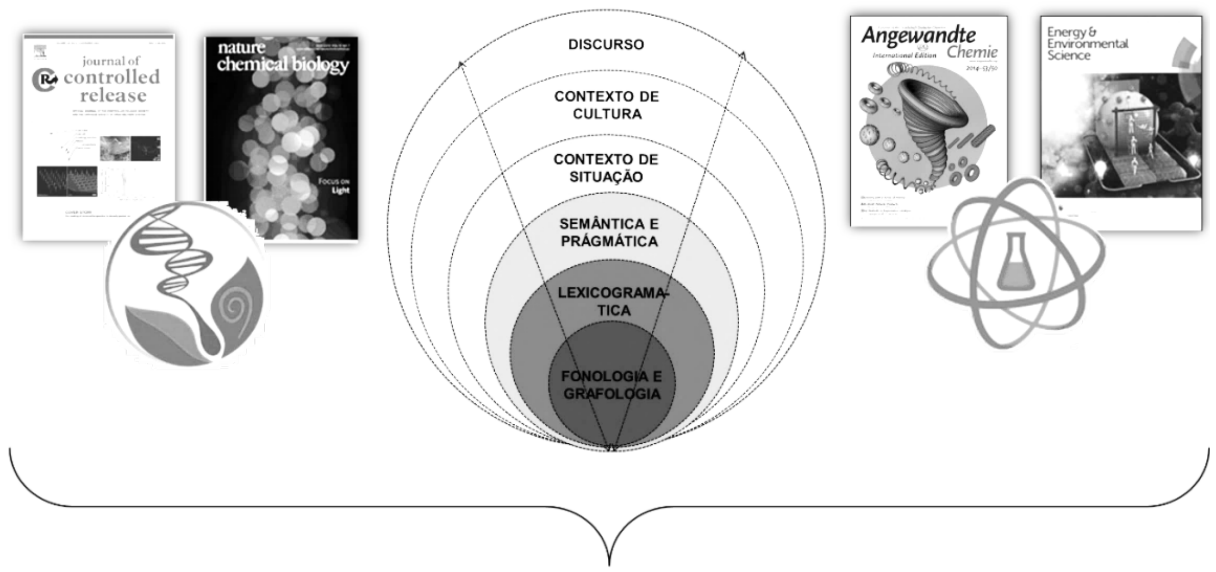

Análise documental

Entrevistas

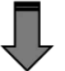

\begin{tabular}{|c|c|c|}
\hline SUMÁRIOS & $\begin{array}{c}\text { INSTRUÇÕES PARA } \\
\text { AUTORES }\end{array}$ & ENTREVISTAS \\
\hline $\begin{array}{l}\text { Apresentam os RAGs } \\
\text { em destaque: } \\
\text { natureza publicitária, } \\
\text { busca atrair a atenção } \\
\text { do leitor. }\end{array}$ & $\begin{array}{l}\text { Instruções sobre a } \\
\text { materialidade e } \\
\text { função do RAG: } \\
\text { sumarizar o tema e as } \\
\text { principais descobertas } \\
\text { da pesquisa; } \\
\text { oferecem pistas sobre } \\
\text { a realização retórica } \\
\text { dos RAGs. }\end{array}$ & $\begin{array}{c}\text { Informam que o RAG: } \\
\text { - Atrai o leitor; } \\
\text { - Não substitui o RA; } \\
\text { - Apresenta as } \\
\text { principais } \\
\text { conclusões e } \\
\text { descobertas do AA e } \\
\text { as etapas mais } \\
\text { relevantes da } \\
\text { pesquisa. }\end{array}$ \\
\hline
\end{tabular}

